\title{
NEW OSAZONE DIAGRAM FOR DETERMINATION OF TWO ALDOSES AND A KETOSE THAT FORM IDENTICAL OSAZONE
}

Nader Noroozi Pesyan ${ }^{1^{*}}$, Jalaladdin Rahbari² and Saeed Elahi-Rad ${ }^{2}$

${ }^{1}$ Faculty of Chemistry, Urmia University, 57159, Urmia, Iran

${ }^{2}$ Department of biology, Faculty of Science, Urmia University, 57153-165, Urmia, Iran

E-mail: nnp403@gmail.com

*Corresponding author: nnp403@gmail.com

\section{ABSTRACT}

A new and interesting osazone diagram was presented for determination and identification of a pair aldoses and a ketose that makes the same osazone. This chart facilitated the finding any aldose and/or ketose yielded the same osazone.

\section{Keywords}

Aldose; Ketose; Osazone diagram; monosaccharide barcode; Mathematical equation

\section{Academic Discipline And Sub-Disciplines}

Educational

\section{SUBJECT CLASSIFICATION}

Mathematics Subject Classification

\section{TYPE (METHOD/APPROACH)}

Theoretical carbohydrate chemical education

\section{Council for Innovative Research}

Peer Review Research Publishing System

Journal: INTERNATIONAL JOURNAL OF RESEARCH IN EDUCATION METHODOLOGY

Vol 5, No 3.

www.ijrem.com , ijremeditor@gmail.com 


\section{INTRODUCTION}

Carbohydrates are an important class of naturally occurring organic compounds, which come by their name because they usually have, or approximate, the general formula $\mathrm{C}_{n}\left(\mathrm{H}_{2} \mathrm{O}\right)_{m}$ with $n$ equal to or greater than three. The known carbohydrates such as sugars, starches, and cellulose, all of which are important for the maintenance of life in both plants and animals [1,2].

The technique was developed by Emil Fischer to identify different sugars and Fischer was able to differentiate the types of sugar by studying the crystals that formed $[3,4]$. Osazones are a class of carbohydrate derivatives formed when sugars are reacted with phenyl hydrazine [5]. Phenyl hydrazine reacts with the carbonyl group in the sugar to create phenyl hydrazone. The hydrazones then react further with the phenyl hydrazine to produce insoluble osazones that appear in crystal form. Their needle-shaped crystals show the position of the first and second carbons [6].

Previously, osazone crystals have been studied using a microscopic technique that it is easy to see the types of crystals that are formed from the different carbohydrates. The different types of crystal like the petals of flowers, are more like cotton wool, are more like needles or even look like fine needles. Sucrose as a non-reducing sugar, however, does not form osazone crystals [7]. An osazone as a sugar derivative and its melting point determined. However, some of the monosaccharides gives identical osazones (e.g. glucose, fructose, mannose). This limits the usefulness of an isolation of the osazone derivative [8]. For instance, owing the same phenyl osazone arises from glucose, mannose and fructose, the configurations of $\mathrm{C} 3, \mathrm{C} 4$ and $\mathrm{C} 5$ carbon atoms must be the same for all three mentioned sugars.

Owing to the troublesome of the working about the synthesis and isolation of osazones, herein, we report a new and easy osazone diagram (osazone chart) for the determination and prediction of any monosaccharide (aldose and/or ketose) that forms identical osazone.

\section{RESULTS AND DISCUSSION}

According to our monosaccharide's new triangular diagram and barcodes [9] (Figs. 1 and 2), we found an interesting and useful correlation between monosaccharides (a pair of aldoses and a ketose that makes identical osazone) and are shown as a new triangular osazone diagram (osazone chart) in Fig. 3. We introduce some notational systems based on mathematical correlation between monosaccharides's new barcode for determination of the pair aldoses that make the same osazone with a ketose. Each pair of aldose and a ketose that forms identical osazone and their corresponding new barcodes are shown as black and red colors, respectively and are located into a pink rectangle (Fig. 3 ).

As we searched in the literature, there are only experimental works were reported about the study and formation of various sugar's osazones [10-14]. For instance, experimentally, D-glucose, D-mannose and D-fructose (as a ketohexose), all three yield the same phenyl osazone [15].

There is no report about common rule for the prediction and finding of an aldose and ketose that make the same osazone without of any experiment. We found mathematical relation between a pair of aldose and a ketose that help us to predict the formation of identical osazone and included in each pink rectangle (Fig. 3). For instance, in the 2-th period ( $n=2$ ), threose $(11 \mathrm{~A})$ and erythrose $(2 \mathrm{~A})$ makes the same osazone with together and with erythrulose $(1 \mathrm{~K})$. Also in the 3 -th period $(n=3)$, arabinose $(21 A)$, ribulose $(2 K)$ and ribose $(3 A)$ have the same osazone and also xylose $(111 A)$, xylulose $(11 K)$ and lyxose $(12 A)$ have too. In the 4-th period $(n=4)$, in the mid-left section, idose $(1111 \mathrm{~A})$, sorbose $(111 \mathrm{~K})$ and gulose $(112 \mathrm{~A})$ together and galactose $(121 \mathrm{~A})$, tagatose $(12 \mathrm{~K})$ and talose $(13 \mathrm{~A})$ forms the same osazone. Also in the mid-right section of 4-th period, glucose $(211 \mathrm{~A})$, fructose $(21 \mathrm{~K})$ and mannose $(22 \mathrm{~A})$ forms the same osazone and finally, altrose (31A), psicose (3K) and allose (4A) forms the same osazone, too (Fig. 3). This chart can also be developing to any synthesized monosaccharide (aldose and/or ketose) that not exists in the nature.

New determination rule for achieve a pair aldose and a ketose that forms identical osazone with using new osazone chart:

This rule contains the following cases;

1) We identify the kind of sugar (aldose and/or ketose with exception of 1,3-dihydroxyacetone as a ketose without of carbon chiral center).

2) We identify the period of sugar which is located in it $(n=2,3, \ldots)$ based on Fig. 3. For example; in 1-th period it is only one distinct sugar (glyceraldehyde, 1A), in 2-th period, there are three sugars including of a pair of aldose and a ketose (threose (11A), erythrulose $(1 \mathrm{~K})$ and erythrose $(2 \mathrm{~A})$ ). In 3-th period, there are six sugars including four aldoses and two ketoses (two aldoses and a ketose are located into a pink rectangle in each mid-left and right sections). In 4-th period, there are twelve sugars, six sugars in the mid-left and six others in the mid-right sections (Fig. 3).

There are some interesting and convenient mathematical relations between two aldoses and a ketose that forms identical osazone as follow.

(a) The mathematical relation for the determination of a ketose that form identical osazone with a pair of aldoses. We have brought three examples for each section for knowledge.

a-1) Conversion of right-hand aldose to related ketose (RA no. $\rightarrow \mathrm{K}$ no.) that make the same osazone (Fig. 4 as representative and equation 1 ); 


$$
\mathrm{K} \text { no. }=\mathrm{RA} \text { no. }-1
$$

Where, $A$ and $K$ are as an aldose and ketose barcodes, respectively. $R A$ is the right-hand aldose (corresponding new barcodes in parenthesis).

For example;

Example 1: Mannose $(22 \mathrm{~A}) \rightarrow$ Fructose $(21 \mathrm{~K}) \square 22-1=21$

Example 2: Talose $(13 \mathrm{~A}) \rightarrow$ Tagatose $(12 \mathrm{~K}) \square 13-1=12$

Example 3: lyxose $(12 \mathrm{~A}) \rightarrow$ Xylulose $(11 \mathrm{~K}) \longrightarrow 12-1=11$

a-2) Conversion of left-hand aldose to related ketose (LA no. $\rightarrow$ K no.) that make the same osazone (Fig. 4 as representative and equation 2);

$$
\mathrm{K} \text { no. }=(\text { LA no. }-1) / 10
$$

For example;

Example 1: Glucose $(211 \mathrm{~A}) \rightarrow$ Fructose $(21 \mathrm{~K}) \quad \square(211-1) / 10=21$

Example 2: Galactose $(121 \mathrm{~A}) \rightarrow$ Tagatose $(12 \mathrm{~K}) \square(121-1) / 10=12$

Example 3: Xylose $(111 \mathrm{~A}) \rightarrow$ Xylulose $(11 \mathrm{~K}) \not(111-1) / 10=11$

(b) The mathematical relation for the determination of an aldose that make the same osazone with a ketose.

b-1) Conversion of ketose to its right-hand aldose (K no. $\rightarrow$ RA no.) that make the same osazone (equation 3);

$$
\mathrm{RA} \text { no. }=\mathrm{K} \text { no. }+1
$$

This equation is the same with the equation (1).

For example;

Example 1: Fructose $(21 \mathrm{~K}) \rightarrow$ Mannose $(22 \mathrm{~A}) \longrightarrow 21+1=22$

Example 2: Sorbose $(111 \mathrm{~K}) \rightarrow$ Gulose $(112 \mathrm{~A}) \Rightarrow 111+1=112$

Example 3: Ribulose $(2 \mathrm{~K}) \rightarrow$ Ribose $(3 \mathrm{~A}) \square 2+1=3$

b-1) Conversion of ketose to its left-hand aldose ( $\mathrm{K}$ no. $\rightarrow$ LA no.) that make the same osazone (equation 4);

$$
L A \text { no. }=(K \text { no. } \times 10)+1
$$

(4)

This equation is also the same with the equation (2).

For example;

Example 1: Fructose $(21 \mathrm{~K}) \rightarrow$ Glucose $(211 \mathrm{~A}) \square(21 \times 10)+1=211$

Example 2: Sorbose $(111 \mathrm{~K}) \rightarrow$ Idose $(1111 \mathrm{~A}) \longrightarrow(111 \times 10)+1=1111$

Example 3: Erythrulose $(1 \mathrm{~K}) \rightarrow$ Threose $(11 \mathrm{~A}) \longrightarrow(1 \times 10)+1=11$

(c) Conversion of right-hand aldose to the left-hand aldose (RA no. $\rightarrow$ LA no.) that make the same osazone.

$$
\text { LA no. }=(\text { RA no. } \times 10)-9
$$

For example;

Example 1: Mannose $(22 A) \rightarrow$ Glucose $(211 A) \square(22 \times 10)-9=211$
Example 2: Talose $(13 A) \rightarrow$ Galactose $(121 A) \square(13 \times 10)-9=121$ 
Example 3: Allose $(4 \mathrm{~A}) \rightarrow$ Altrose $(31 \mathrm{~A}) \longrightarrow(4 \times 10)-9=31$

(d) Conversion of left-hand aldose to the right-hand aldose (LA no. $\rightarrow$ RA no.) that make the same osazone.

$$
\text { RA no. }=(\text { LA no. }+9) / 10
$$

This equation is also the same with the equation (5).

For example;

Example 1: Glucose $(211 \mathrm{~A}) \rightarrow$ Mannose $(22 \mathrm{~A}) \longrightarrow(211+9) / 10=22$

Example 2: Galactose $(121 \mathrm{~A}) \rightarrow$ Talose $(13 \mathrm{~A}) \longrightarrow(121+9) / 10=13$

Example 3: Xylose $(111 \mathrm{~A}) \rightarrow$ Lyxose $(12 \mathrm{~A}) \longrightarrow(111+9) / 10=12$

Finally, we obtained the new osazone chart with analyzing the mentioned above mathematical relations (Fig. 3).

\section{FIGURES/CAPTIONS}

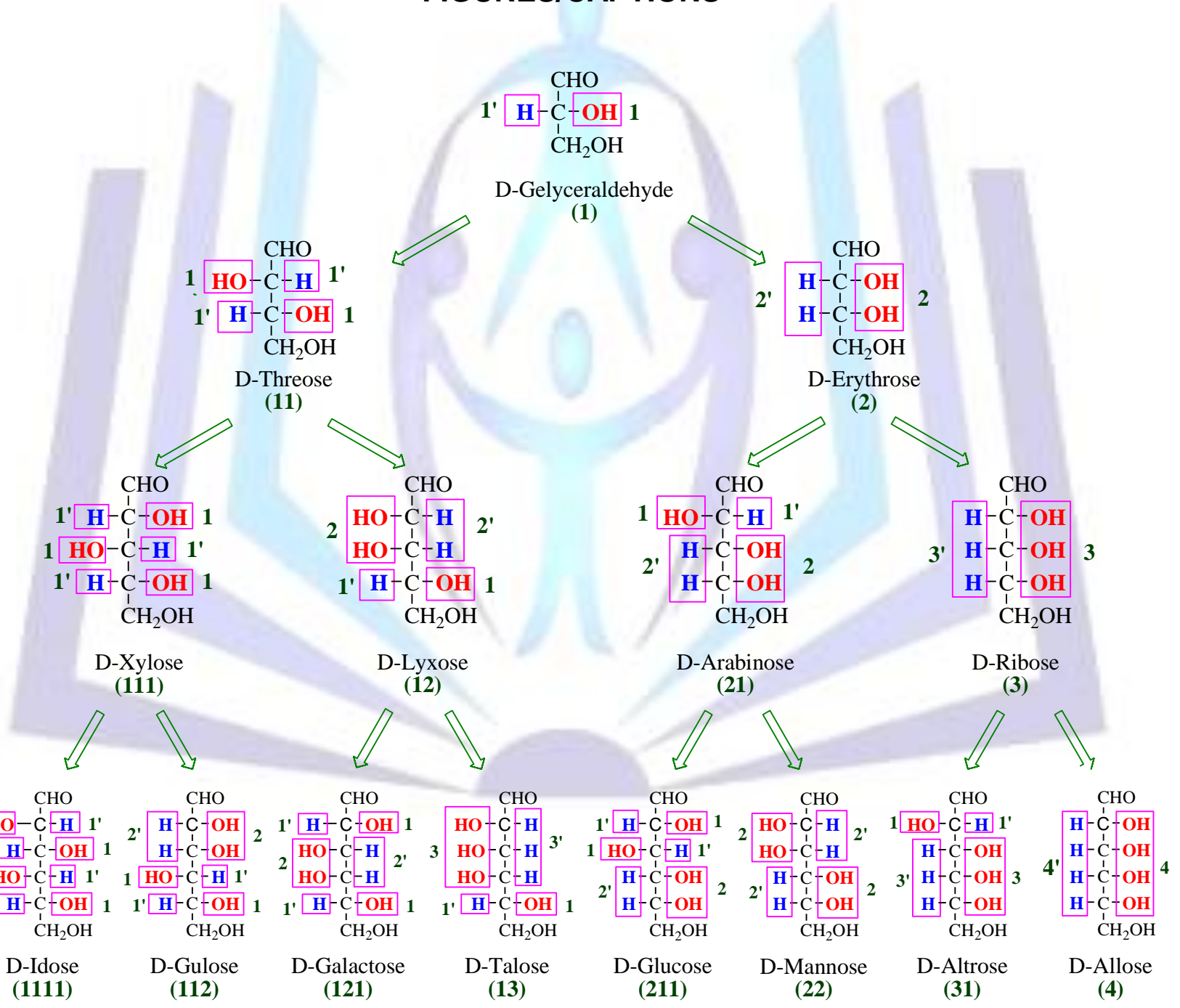

Fig 1: Presented D-aldoses's new tree diagram and corresponding new barcodes (dark green in parenthesis) 


$$
\begin{aligned}
& \mathrm{CH}_{2} \mathrm{OH} \\
& \stackrel{\mathrm{C}}{\mathrm{C}}=\mathrm{O} \\
& \mathrm{I} \mathrm{CH}_{2} \mathrm{OH}
\end{aligned}
$$

Dihydroxyacetone

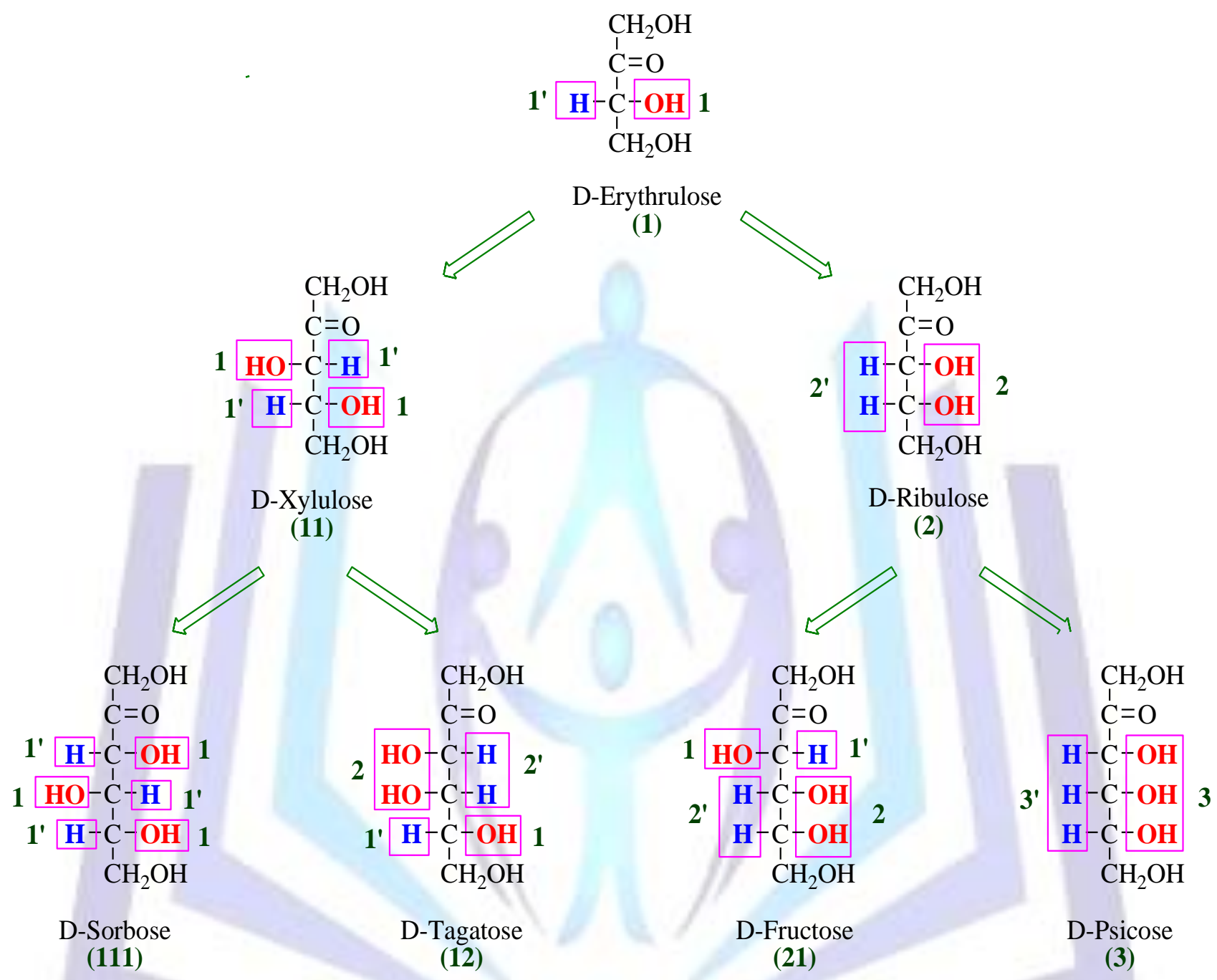

Fig 2: Presented D-ketoses's new tree diagram and corresponding new barcodes (dark green in parenthesis) 


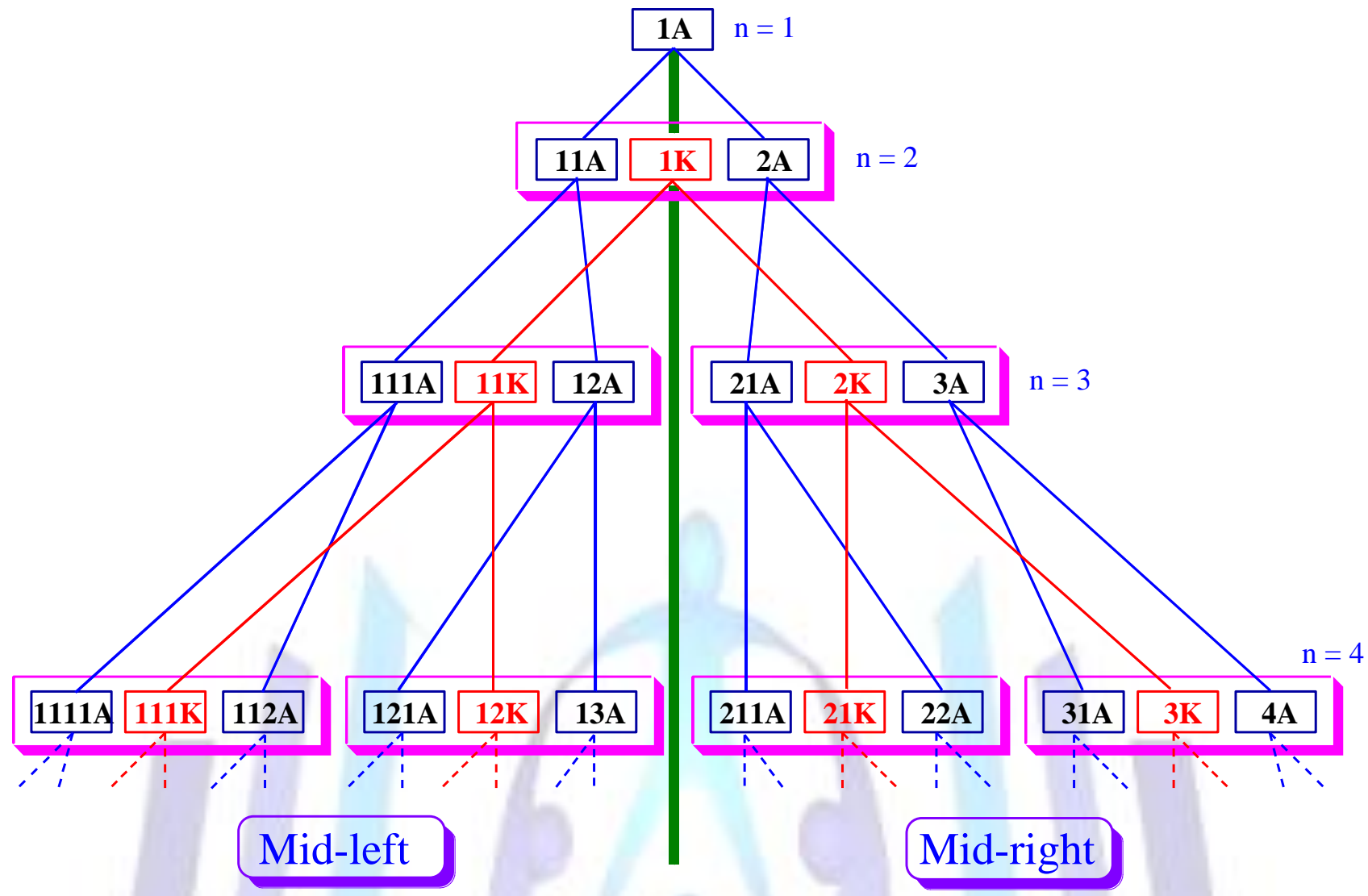

Fig 3: New presented triangular osazone diagram (chart) for sugars for the identification and determination of a pair aldose and a ketose that make the same osazone ( $A=$ Aldose (black) and $K=$ Ketose (red)). These barcodes based on new presented sugar's barcodes

\section{Fructose $(21 \mathrm{~K})$ and mannose $(22 \mathrm{~A})$ that forms identical osazone}

Fig 4: Representatively, a portion of new presented triangular osazone diagram (chart) for glucose (211A),

\section{ACKNOWLEDGMENTS}

We gratefully acknowledge the Research Council of Urmia University.

\section{REFERENCES}

[1] Carey, F. A. 1992 "Organic Chemistry", 2th ed., McGraw-Hill, New York.

[2] McMurry, J. E., Ballantine, D. S., Hoeger, C. A., Peterson, V. E. and Castellion, M. E. 2009 "Fundamentals of General, Organic, and Biological Chemistry", 6th ed.,Prentice Hall,Upper Saddle River, NJ.

[3] Shriner, R. L., Fuson, R. C., Curtin, D. Y. and Morrill, T. C. 1980 "The systematic identification of organic compounds", 6 th ed., John Wiley \& Sons, New York.

[4] http://www.ehow.com/info_8392949_different-osazone-crystals.html\#ixzz2qCRIckt5(accessed date: 9, Feb., 2014).

[5] Mester, L., El Khadem, H. and Horton, D. 1970 "Structure of saccharide osazones". J. Chem. Soc. C: Org., $18,2567$.

[6] http://www.ehow.com/info_8392949_different-osazone-crystals.html\#ixzz2qCQ4vUuj(accessed date: 9, Feb., 2014).

[7] http://www.ehow.com/info_8392949_different-osazone-crystals.html\#ixzz2qCQcGx4u(accessed date: 9, Feb., 2014). 
[8] Pavia, D. L., Lampman, G. M., Kriz, G. H. and Engel, R. G. 2011 “A Small Scale Approach to Organic Laboratory Techniques", 3th ed.,Cengage Learning.

[9] Rahbari, J., Elahirad, S. and Noroozi Pesyan, N. 2014 A new and simple method for drawing of the monosaccharide Fischer projection based on new monosaccharide's barcodes. Chem. Educ. J. (JPN), 16, URL = http://chem.sci.utsunomiya-u.ac.jp/cejrnlE.html

[10] Hassid, W. and McCready, R. 1942 Identification of sugars by microscopic appearance of crystalline osazones. Ind. Eng. Chem. Anal. Ed., 14 (8), 683-686.

[11] Sallam, M. A. E. 1980 Studies on anhydro-osazones. Structure and anomeric configuration of the 3,6-anhydroosazone derivatives obtained from D-galacto-2-heptulose phenylosazone. Carbohydrate Res., 85, 93-105.

[12] Sallam, M. A. E. and Hegazy, E. I. A. 1981 Studies on 3-epimeric 2-hexulose phenylosazones. structure and anomeric configuration of the 3,6-anhydro-osazone derivatives obtained from D-arabino- and D-ribo-2-hexulose phenylosazone. Carbohydrate Res., 95, 177-187.

[13] Sallam, M. A. E., Hegazy, E. I. A., Whistler, R. L., Markley, J. L. and Croll, D. H. 1982 Studies on 3-epimeric L-2hexulose phenylosazones. Structure and anomeric configuration of the 3,6-anhydro-osazone derivatives obtained from L-xylo- and L-lyxo-2-hexulose phenylosazone. Carbohydrate Res., 102, 197-206.

[14] Somogyi, L. 1986 Synthesis of mixed osazone derivatives by regioselective electrophilic substitution. Carbohydrate Res., 152, 316-322.

[15] Levy,D. D. E. and Fügedi, P. 2006 “The Organic Chemistry of Sugar”, Taylor and Francis, CRC press, Boca Raton, FL.

\section{Author' biography with Photo}

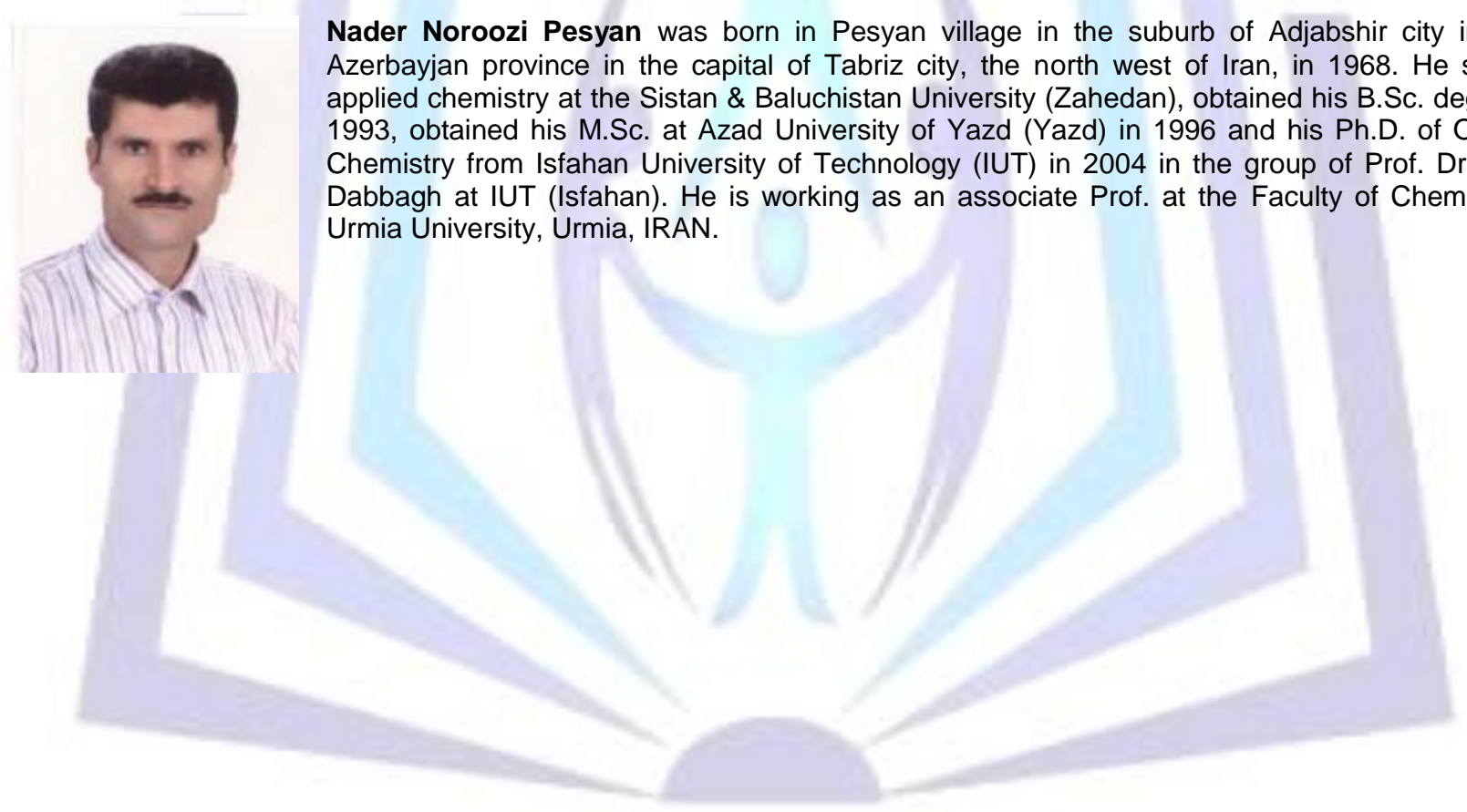

